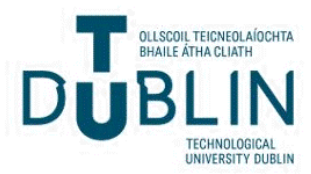

Technological University Dublin

ARROW@TU Dublin

Articles

Antenna \& High Frequency Research Centre

2011-8

\section{Wideband Dual-Frequency Dual-Polarized Dipole-Like Antenna}

\author{
Xiulong Bao \\ Technological University Dublin, xiulong.bao@tudublin.ie \\ Max Ammann \\ Technological University Dublin, max.ammann@tudublin.ie
}

Follow this and additional works at: https://arrow.tudublin.ie/ahfrcart

Part of the Systems and Communications Commons

\section{Recommended Citation}

Bao, X.L. \& Ammann, M.J. (2011). Wideband Dual-Frequency Dual-Polarized Dipole-Like Antenna, IEEE Antennas and Wireless Propagation Letters, vol. 10, pp. 831-834, 08/2011. doi:10.1109/ LAWP.2011.2164609

This Article is brought to you for free and open access by the Antenna \& High Frequency Research Centre at ARROW@TU Dublin. It has been accepted for inclusion in Articles by an authorized administrator of ARROW@TU

Dublin. For more information, please contact

arrow.admin@tudublin.ie, aisling.coyne@tudublin.ie, gerard.connolly@tudublin.ie.

Funder: Science Foundation Irealnd

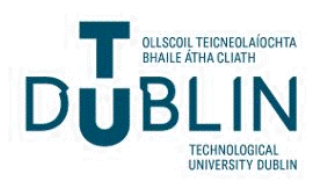




\title{
Wideband Dual-Frequency Dual-Polarized Dipole-Like Antenna
}

\author{
X. L. Bao Member, IEEE M. J. Ammann, Senior Member, IEEE
}

\begin{abstract}
A wideband dual-frequency dual-polarized printed antenna is proposed for LTE, WLAN and UWB systems. The dualband antenna provides wide impedance bandwidths of $74 \%$, with respect to the centre frequency of $2.725 \mathrm{GHz}$, and $39 \%$ with respect to the centre frequency of $7.15 \mathrm{GHz}$. An open slot in the ground plane between the feed arms provides an orthogonal path to realize an embedded circularly-polarized band at $2.35 \mathrm{GHz}$ with an axial ratio bandwidth of $16 \%$. Dual-band characteristics are achieved by an asymmetrical dipole-like element and the coupling configuration between the T-shaped feed line and the wide ground plane slot.
\end{abstract}

\section{INTRODUCTION}

The demand for low-cost antenna solutions is increasing with the continued expansion of the wireless communication industry. In particular, increased consideration is given to printed multiband, multimode and dual-polarized antennas. For the wireless local area network (WLAN), circularpolarization (CP) is often a good choice because of reduced multipath and antenna orientation constraints. Thus, multiband linear and circular polarization performance is required in a single antenna.

In recent decades, microstrip patch, slot, and printed monopole antennas have been introduced to achieve dualfrequency linear polarization performances [1-4]. A stacked Tshaped printed monopole [5] and a CPW-fed planar monopole with slotted radiating element [6] were shown to realize dualfrequency linear performance for WLANs. A dual band printed dipole was reported in 2000 [7] and subsequently an antipodal dipole loaded with split ring resonators gave dual frequency linear performance [8].

A multilayer dual-frequency circular patch antenna was shown to achieve orthogonal CP performance over two bands [9] and a triangular microstrip antenna was proposed [10] to provide two resonant modes realizing a linear performance for GSM and CP in the GPS band; but both bandwidths are less than $10 \%$. A printed antenna was recently introduced achieving CP over a single band with an axial ratio bandwidth (AR) of $23 \%$ [11]. This antenna comprised asymmetrical linear elements and a narrow ground plane slit which generates the necessary orthogonal surface currents, in the dipole, feedline and ground plane for CP.

In this paper, a dual frequency printed dipole-like antenna is presented providing wideband circular and linear polarization performance covering LTE (1710-2690 MHz), WLAN (2400$2484 \mathrm{MHz})$ and UWB band groups 3 and 6 (6.0-8.5 GHz).

Manuscript received $10^{\text {th }}$ June 2011. This work was supported by Science Foundation Ireland under Grant 09/SIRG/11644.

X. L. Bao and M. J. Ammann are with the Antenna and High Frequency Research Centre, Dublin Institute of Technology, Dublin 8, Ireland (phone: 353-14024905; fax: 353-14024690; e-mail: max.ammann@dit.ie).

\section{THE GEOMETRY OF THE PROPOSED PRINTED ANTENNA}

The antenna geometry shown in Figure 1 comprises a dipolelike structure with tapered arms of unequal length and a wide gap between the feed lines, forming an open-ended slot which cuts into the ground plane. It is fed using a T-shaped microstrip stepped line which couples equally to both slot edges and connects to the feedline of the shorter arm using a via. This acts as a balun for the low frequency mode [11-12]. The $90^{\circ}$ phase perturbed orthogonal modes are realized by a combination of the $\mathrm{x}$-directed dipole arm currents and the $\mathrm{y}$ directed currents on the open-ended slot structure. The longer dipole arm and the slot are approximately one quarter of a guided wavelength long at $2.35 \mathrm{GHz}$. The $\mathrm{CP}$ mechanism for the antenna is similar to that in [11] where a detailed description can be found.

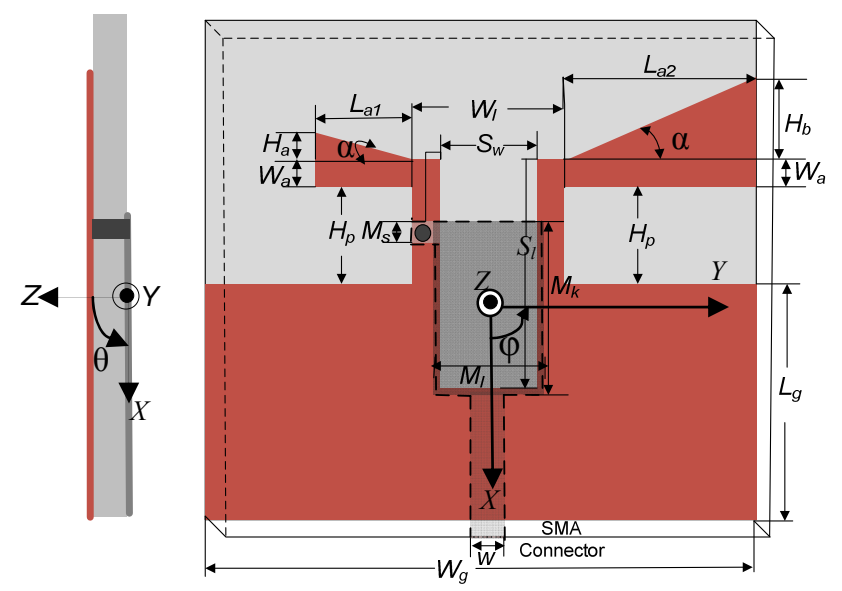

(a) Profile

(b) Top and bottom layers

Figure 1. The geometry of the proposed antenna

However, the antenna proposed here differs in the following ways; in order to realize an antenna with a significantly wider impedance bandwidth and provide a second higher frequency band, a wide open-ended slot is used in conjunction with a Tshaped microstrip feed section. This enables good matching for the higher order mode. The tapering on the arms improve the bandwidth, reducing the lower edge frequency, enabling a smaller antenna. The AR bandwidth of the embedded CP band for the recomposed antenna is reduced to $16 \%$ compared to $23 \%$ in [11]. The surface current distribution for the upper band is shown in Figure 2. Simulations were carried out using the time domain solver of CST MWS. It is seen that the excitation of the upper mode is dependent on the coupling between the $\mathrm{T}$ shaped feedline and the wide slot. The length of the stepped 
feed section $M_{k}$, is approximately three quarters of a guided wavelength at $7.5 \mathrm{GHz}$

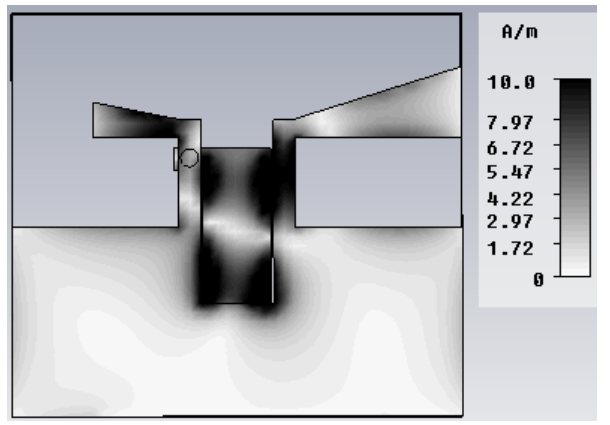

Figure 2. The simulated surface current distribution for $7.5 \mathrm{GHz}$.

The antenna is fabricated on a Taconic RF35 substrate (45 $\mathrm{mm} \times 50 \mathrm{~mm} \times 1.57 \mathrm{~mm})$ with $\varepsilon_{\mathrm{r}}=3.5$. The selected parameters are: $L_{a 1}=9.5 \mathrm{~mm}, L_{a 2}=18.5 \mathrm{~mm}, W_{a}=2.0 \mathrm{~mm}$, $W_{l}=13.0 \mathrm{~mm}, W=3.0 \mathrm{~mm}, S_{w}=8.0 \mathrm{~mm}, S_{l}=20.5 \mathrm{~mm}, M_{s}=$ $2.5 \mathrm{~mm}, M_{k}=18.5 \mathrm{~mm}, M_{l}=7.6 \mathrm{~mm}, H_{p}=10.0 \mathrm{~mm}, H_{a}=3.0$ $\mathrm{mm}, H_{b}=5.5 \mathrm{~mm}, \alpha=16^{\circ}$. The ground plane length $L_{g}$ is $21 \mathrm{~mm}$. The via radius is $0.65 \mathrm{~mm}$ and is located at the coordinate $(-8.8 \mathrm{~mm},-5.3 \mathrm{~mm})$ in the XoY plane.

\section{NUMERICAL AND MEASURED RESULTS}

Figure 3 shows the simulated and measured $S_{l 1}$. The measured $10 \mathrm{~dB}$ impedance bandwidth for the first frequency band is $2.03 \mathrm{GHz}(1.71 \mathrm{GHz}$ to $3.74 \mathrm{GHz})$ corresponding to $74 \%$. The measured $3 \mathrm{~dB}$ AR bandwidth is approximately 380 $\mathrm{MHz}(2.16 \mathrm{GHz}$ to $2.54 \mathrm{GHz})$ providing

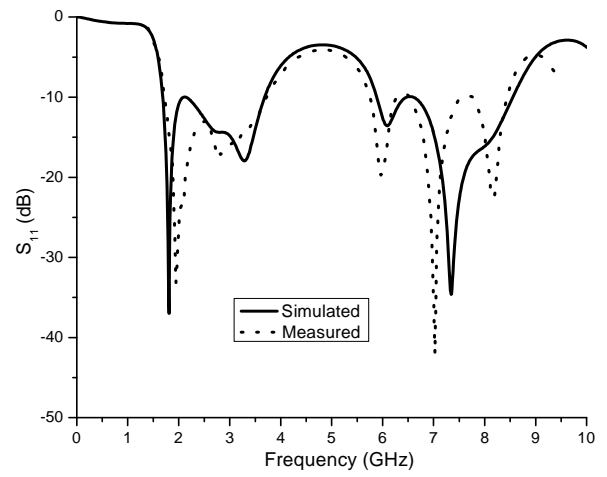

Figure 3. Measured and simulated $\mathrm{S}_{11}$

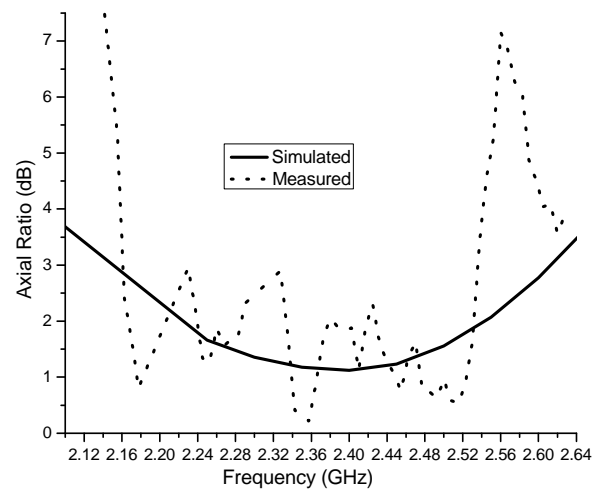

Figure 4. Measured and simulated axial-ratio
CP for the WLAN bands, as shown in Figure 4. For the second band, the impedance bandwidth is approximately 2.8 $\mathrm{GHz}(5.75 \mathrm{GHz}$ to $8.55 \mathrm{GHz})$. The antenna is linearly polarized in this band. These bands include LTE (1710 -2690 $\mathrm{MHz})$, WiMAX and the UWB bandgroups 3 and 6 (6.0 -8.5 $\mathrm{GHz}$ ). Hence, the antenna provides a matched bandwidth of $74 \%$ for the first band with an embedded circularly-polarized band (16\% AR bandwidth) and a second band of 39\% bandwidth with linearly-polarized performance.

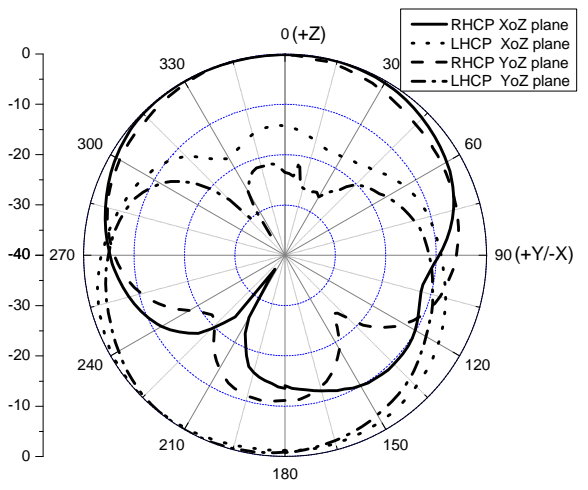

Figure 5. Measured RHCP and LHCP patterns (XoZ and YoZ) at $2.45 \mathrm{GHz}$.

For the $\mathrm{CP}$ band, the measured RHCP and LHCP radiation patterns at $2.45 \mathrm{GHz}$ in the $\mathrm{XoZ}$ and $\mathrm{YoZ}$ planes are shown in Figure 5 normalised to a peak gain of $2.4 \mathrm{dBic}$. For the linear

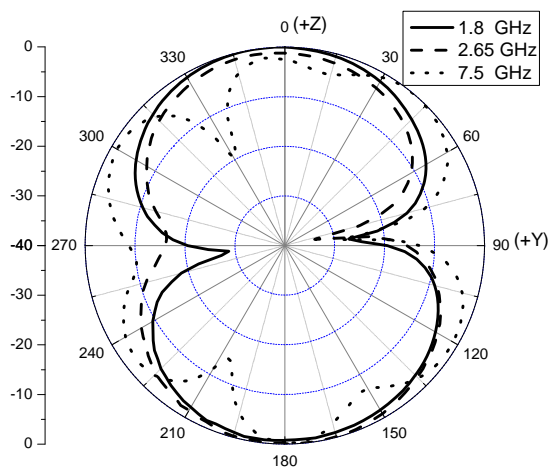

(a) YoZ plane $\left(E_{\theta}\right)$

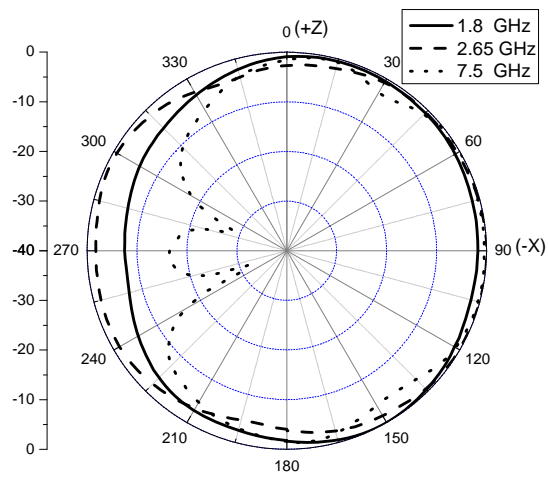

(b) XoZ plane $\left(E_{\varphi}\right)$

Figure 6. Measured radiation patterns at $1.8 \mathrm{GHz}, 2.65 \mathrm{GHz}$ and $7.5 \mathrm{GHz}$ 
polarized band, the radiation patterns in the XoZ plane and YoZ planes were measured at $1.8 \mathrm{GHz}, 2.65 \mathrm{GHz}$, and 7.5 $\mathrm{GHz}$ and are shown in Figure 6. The peak gains were found to be $2.5 \mathrm{dBi}, 2.4 \mathrm{dBi}$, and $4.0 \mathrm{dBi}$, respectively. The efficiency varied across the band from $-0.3 \mathrm{~dB}$ at $1.8 \mathrm{GHz}$ to $-2.5 \mathrm{~dB}$ at $8.5 \mathrm{GHz}$.

\section{PARAMETRIC STUDY}

A parametric study of key parameters based on CST MWS is given to assist with the design procedure. As the flare angle $\alpha$ of the taper is changed, $H_{a}$ and $H_{b}$ are also both varied. As the flare angle $\alpha$ is increased from $0^{\circ}$ to $32^{\circ}$, the lower edge frequency decreases from $1.88 \mathrm{GHz}$ to $1.56 \mathrm{GHz}$ as shown in Figure 7. The CP centre frequency is also shifted downwards but the AR degrades with increasing angle $\alpha$ as shown in Figure 8. The use of the wide tapered structure enables antenna miniaturization.

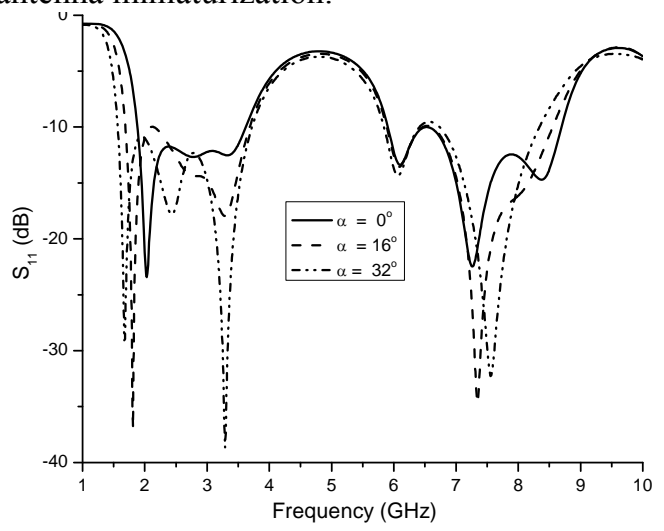

Figure 7. Simulated $\mathrm{S}_{11}$ for different flare angle $\alpha$ (with $L_{a 1}=9.5 \mathrm{~mm}, S_{w}=$ $8.0 \mathrm{~mm}, S_{L}=20.5 \mathrm{~mm}$ )

The effects of the short arm length $L_{a l}$ on the high frequency are shown in Figure 9. It is found the impedance bandwidth of the both bands increase as the length is increased. But for the low frequency band, the $\mathrm{CP}$ centre frequency shifts downwards with a degradation in AR as shown in Figure 10

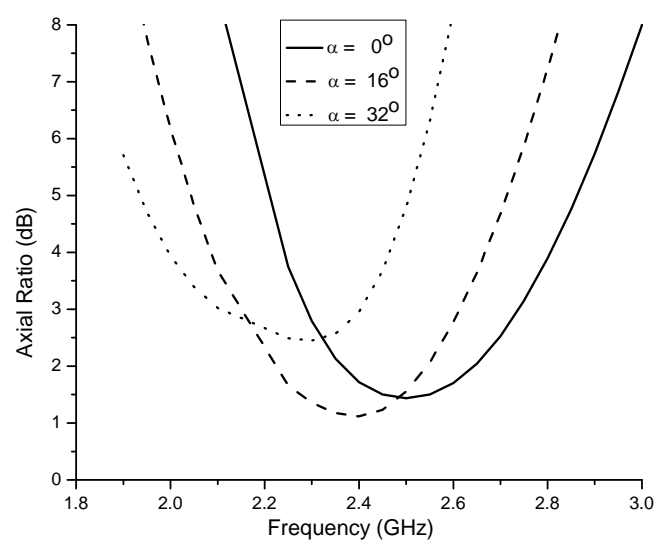

Figure 8. Simulated axial ratio for different flare angle $\alpha$ (with $L_{a l}=9.5 \mathrm{~mm}$, $\left.S_{w}=8.0 \mathrm{~mm}, S_{L}=20.5 \mathrm{~mm}\right)$

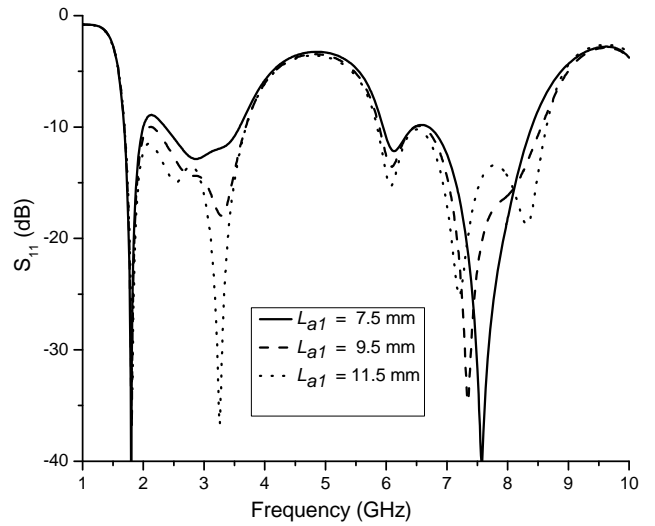

Figure 9. Simulated $\mathrm{S}_{11}$ for different $L_{a l}$ (with $\alpha=16^{\circ}, S_{w}=8.0 \mathrm{~mm}$, $\left.S_{L}=20.5 \mathrm{~mm}\right)$

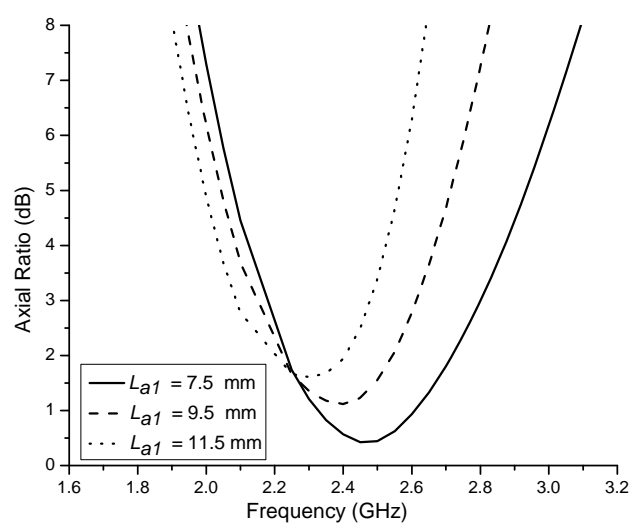

Figure 10. Simulated axial ratio for different $L_{a 1}$ (with $\alpha=16^{\circ}, S_{w}=$ $8.0 \mathrm{~mm}, S_{L}=20.5 \mathrm{~mm}$ )

The higher frequency mode is heavily dependent on the open-ended slot parameters, $S_{W}$ and $S_{L}$. The frequency ratio $f_{2} / f_{1}$ can be changed from 2.67 to 3.14 as the slot width $S_{W}$ is increased from 5 to $8 \mathrm{~mm}$ as illustrated in Figure 11. The bandwidth for the lower frequency shows weak sensitivity to this parameter. The AR bandwidth will increase slightly as $S_{W}$ is increased (Figure 12).

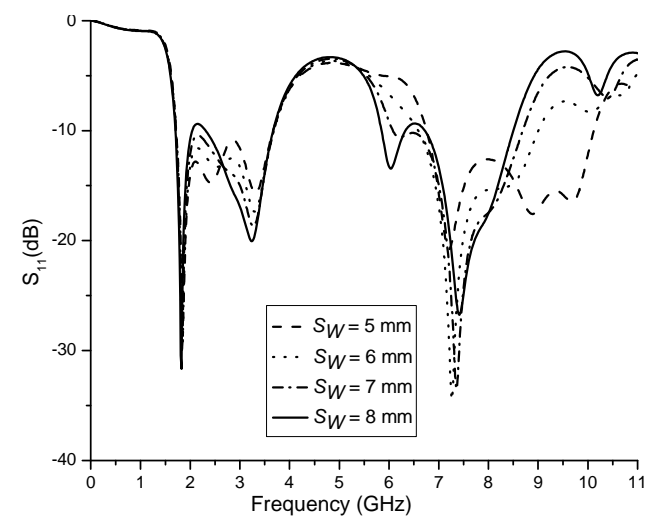

Figure 11. Simulated $\mathrm{S}_{11}$ for different $S_{W}\left(\right.$ with $\alpha=16^{\circ}, L_{a l}=9.5 \mathrm{~mm}$, $\left.S_{L}=20.5 \mathrm{~mm}\right)$ 


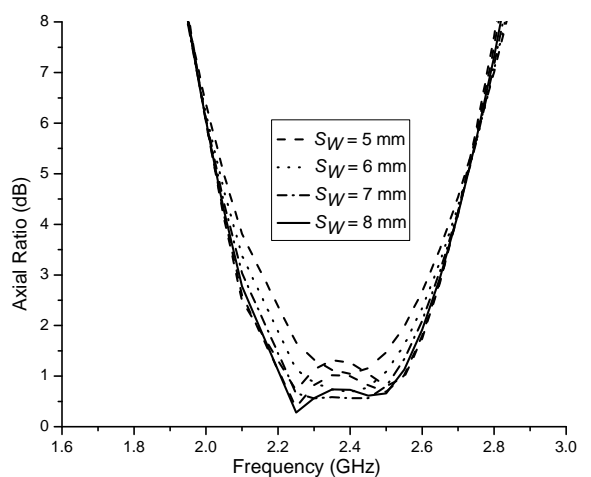

Figure 12. The simulated $\mathrm{S}_{11}$ for different $S_{W}$ (with $\alpha=16^{\circ}, L_{a l}=$ $9.5 \mathrm{~mm}, S_{L}=20.5 \mathrm{~mm}$ )

Figure 13 shows the $S_{11}$ sensitivity to the length of the openended slot $S_{L}$. The upper edge frequency for the first frequency band is shifted upwards and the AR bandwidth is decreased as the slot length $S_{L}$ is decreased. Figure 14 illustrates the AR curves for variation in $S_{L}$. It should also be noted that the $S_{11}$ and $\mathrm{AR}$ are dependent on ground plane dimensions.

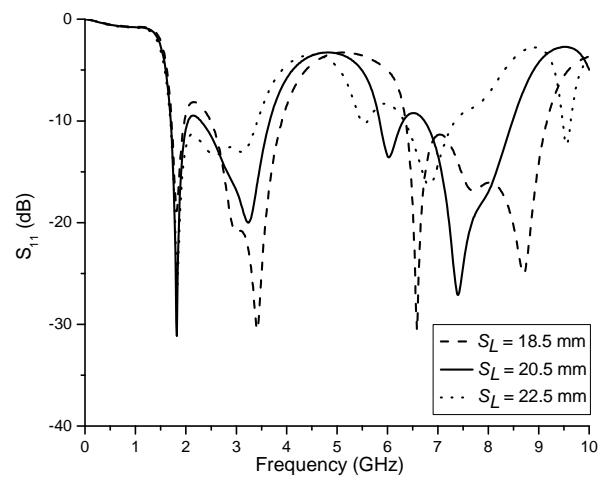

Figure 13. The simulated $\mathrm{S}_{11}$ for different $S_{L}$ (with $\alpha=16^{\circ}, L_{a l}=$ $9.5 \mathrm{~mm}, S_{W}=8.0 \mathrm{~mm}$ )

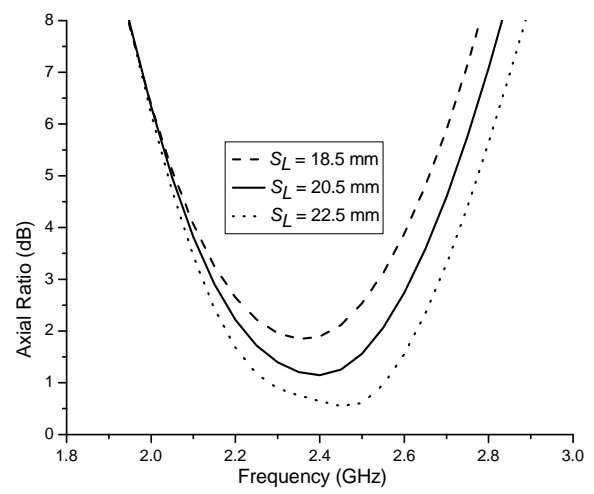

Figure 14. The simulated axial ratio for the different $S_{L}$ (with $\alpha=16^{\circ}$, $L_{a l}=9.5 \mathrm{~mm}, S_{W}=8.0 \mathrm{~mm}$ )

\section{CONCLUSION}

A dual-frequency printed antenna providing wideband circular and linear polarization is proposed. The impedance bandwidths are $74 \%$ and $39 \%$ for the first and second bands. A $16 \%$ embedded CP band is realized within the first band. Gains achieved are appropriate for multimode wireless communications systems in the LTE, WLAN and UWB spectra.

\section{REFERENCES}

[1]. J. H. Lu, C. L. Tang, K. L. Wong, Novel Dual-Frequency and BroadBand Designs of Slot-Loaded Equilateral Triangular Microstrip Antennas, IEEE Trans. Antennas Propag, Vol. 48, No.7, 2000, pp. 1048-1054.

[2]. N. Misran, R. Cahill, and V. F. Fusco, Concentric Split Ring Element for Dual Frequency Reflectarray Antennas, Electronic Letters, Vol. 39, No.25, 2003, pp. 1776-1777.

[3]. J. S. Chen, Dual-Frequency Annular-Ring Slot Antennas Fed by CPW Feed and Microstrip Line Feed, IEEE Trans. Antennas Propag, Vol. 53, No.1, 2005, pp. 569-571.

[4]. M. N. Suma, R. K. Raj, M. Joseph, P. C. Bybi, et al., A Compact Dual Band Planar Branched Monopole Antenna for DCS/2.4-GHz WLAN Applications, IEEE Microwave Wireless Components Letters, Vol.16, No.5, 2006, pp. 275-277.

[5]. Y. L. Kuo, and K. L. Wong, Printed Double-T Monopole Antenna for 2.4/5.2 GHz Dual-Band WLAN Operations, IEEE Trans Antennas Propag., Vol. 51, No.9, 2003, pp.2187-2192.

[6]. W. C. Liu, Wideband Dual-Frequency Double Inverted-L CPW-Fed Monopole Antenna for WLAN Application, IEE Proc Microw. Antennas Propag. Vol. 152, No.6, 2005, pp. 505-510.

[7]. Y. H. Suh, K. Chang, Low Cost Microstrip-Fed Dual Frequency Printed Dipole Antenna for Wireless Communications, Electronic Letters, Vol.36, No.14, 2000, pp. 1177-1179.

[8]. F. J. Herraiz-Martinez, L. E. Garcia-Munoz, D. Gonzalez-Ovejero, V. González-Posadas and D. Segovia-Vargas, Dual-Frequency Printed Dipole Loaded With Split Ring Resonators, IEEE Antennas and Wireless Propagation Letter, Vol.8, 2009, pp. 137 - 140.

[9]. R. Shavit, Y. Israeli, L. Pazin, and Y. Leviatan, Dual Frequency Circularly Polarised Microstrip Antenna, IEE Proc.- Microw. Antennas Propag., Vol. 152, No.4, 2005, pp. 267-272.

[10]. J. S. Row, and K. W. Lin, Low-profile Design of Dual-frequency and Dual-polarised Triangular Microstrip Antennas, Electronic Letters, vol. 40, (3), 2004, pp. 156-157.

[11]. X. L. Bao, M. J. Ammann, P. McEvoy, Microstrip-Fed Wideband Circularly Polarized Printed Antenna, IEEE Trans. Antennas Propag, vol. 58, (10), 2010, pp. 3150-3156.

[12]. L. C. Kuo, and H. R. Chuang, and Y. C. Kan, A Study of Planar Printed Dipole Antennas for Wireless Communication Applications, Journal of Electromagnetic Waves and Applications, vol. 21, No. 5, 2007, pp. 637-652. 